\title{
Sea State Estimation Using Vessel Response in Dynamic Positioning
}

\author{
H. Brodtkorb, Astrid; Nielsen, Ulrik Dam; J. Sørensen, Asgeir
}

Published in:
Applied Ocean Research

Link to article, DOI:

10.1016/j.apor.2017.09.005

Publication date:

2018

Document Version

Peer reviewed version

Link back to DTU Orbit

Citation (APA):

H. Brodtkorb, A., Nielsen, U. D., \& J. Sørensen, A. (2018). Sea State Estimation Using Vessel Response in Dynamic Positioning. Applied Ocean Research, 70, 76-86. https://doi.org/10.1016/j.apor.2017.09.005

\section{General rights}

Copyright and moral rights for the publications made accessible in the public portal are retained by the authors and/or other copyright owners and it is a condition of accessing publications that users recognise and abide by the legal requirements associated with these rights.

- Users may download and print one copy of any publication from the public portal for the purpose of private study or research.

- You may not further distribute the material or use it for any profit-making activity or commercial gain

- You may freely distribute the URL identifying the publication in the public portal

If you believe that this document breaches copyright please contact us providing details, and we will remove access to the work immediately and investigate your claim 


\title{
Sea State Estimation Using Vessel Response in Dynamic Positioning
}

\author{
Astrid H. Brodtkorbb ${ }^{a, *}$, Ulrik D. Nielsen ${ }^{a, b}$, Asgeir J. Sørensen ${ }^{a}$ \\ ${ }^{a}$ Centre for Autonomous Marine Operations (NTNU AMOS), Department of Marine Technology, \\ Norwegian University of Science and Technology (NTNU), Otto Nielsens vei 10, 7491 Trondheim, Norway \\ ${ }^{b}$ DTU Mechanical Engineering, Technical University of Denmark, Kgs. Lyngby, Denmark
}

\begin{abstract}
This paper presents a novel method for estimating the sea state parameters based on the heave, roll and pitch response of a vessel in dynamic positioning (DP), i.e., without forward speed. The algorithm finds the wave spectrum estimate from the response measurements by directly solving a set of linear equations, and as a result it is computationally efficient. The main vessel parameters are required as input. Apart from this the method is signal-based, with no assumptions on the wave spectrum shape. Performance of the proposed algorithm is demonstrated on full-scale experimental DP data of a vessel in three different sea states at head, bow, beam, quartering and following sea waves, respectively.

Keywords: Sea state estimation, Vessel response, Dynamic positioning, Closed-form expressions
\end{abstract}

\section{Introduction}

Complex marine operations are moving further from shore, into deeper waters, and harsher environments, see Sørensen [1]. The operating hours of a vessel are weather dependent, and good knowledge of the prevailing weather conditions may ensure costefficient and safe operations. Recently, there has been a lot of focus on increasing the level

${ }^{*}$ Corresponding author at: Centre for Autonomous Marine Operations (NTNU AMOS), Department of Marine Technology, Norwegian University of Science and Technology (NTNU), Otto Nielsens vei 10, 7491 Trondheim, Norway.

Email address: astrid.h.brodtkorb@ntnu.no (Astrid H. Brodtkorb) 
of autonomy in marine operations, see Ludvigsen et al. [2], and having a fast and reliable method for obtaining a sea state estimate is useful both in the control and in decision support systems to aid the decision making process, with or without the operator onboard the vessel.

Several methods exist for obtaining information about the sea state. Wave rider buoys are present at fixed locations, usually near the coast, providing accurate measurements for specific sites. Some vessels have installed wave radar, see [3], but these systems may be expensive to install, require frequent calibration, see [4] and [5], and in the case of large vessel motion the measurement quality is degraded. Satellite image quality is affected by the resolution and if the cloud cover is low, and in general, weather data may lag around six hours.

Today, the majority of marine vessels are equipped with sensors that gather vast amounts of data regarding the operational state, fuel consumption, hull girder stresses, acceleration, attitude and position, to name a few. In this sense, marine vessels are indirectly equipped with sea state measuring systems, since the sensor measurements can be used to infer about the on-site sea state, in a similar way as is done with traditional wave rider buoys. Estimating the sea state based on vessel motions has been explored extensively over the last 10-15 years, e.g., $[6,7,8,9]$, see Nielsen [10] for an overview of the different methods. One proposed method is called the wave buoy analogy, where the ship motions in 6 degrees of freedom (DOF), or other global ship responses such as hull girder stresses, are transformed into the frequency domain, and an estimate of the wave spectrum is obtained by means of parametric or Bayesian modeling. The vessel is implicitly assumed to be in stationary conditions if not elaborate procedures are applied $[11,12]$.

For advanced controller schemes, e.g., hybrid or switching control, sea state parameters estimated using computationally efficient algorithms are sought. Online sea state estimates from rapid schemes, can be used to manipulate parameters in the control law directly, or be input to performance monitoring functions and risk assessment models that choose the best algorithms available. There are many computationally efficient schemes for estimating the peak frequency of the waves, however algorithms for estimating the wave height and direction are rare. Belleter et al. [13] presents a time-domain method for estimating the 
peak frequency of encounter in order to detect parametric rolling, and Brodtkorb et al. [14] uses the response spectrum in heave and pitch to estimate the peak frequency of the sea state for use in controllers. Nielsen et al. [15] estimates the amplitude, phase and frequency of a regular wave, making a step towards a sea state estimation algorithm that is computationally efficient, and provides the wave height and direction estimate, in addition to the peak frequency. On a related note, the vessel response history itself may also be used for predicting the vessel response deterministically (30-60 seconds) ahead of time using the correlation structure in the time history process, see Nielsen et al. [16].

This paper proposes a computationally efficient and robust sea state estimation algorithm that provides an estimate of the wave spectrum, from which sea state parameters such as the significant wave height $H_{s}$, peak period $T_{p}$ (or other characteristic periods), and the relative wave direction $\beta$ can be derived. The sea state estimation algorithm is non-parametric, i.e., there are no assumptions on the shape of the wave spectrum, and so the sea state estimate is obtained through solving a set of linear equations relating the wave spectrum to the response measurements via motion response amplitude operators (RAO). In this initial study, the RAOs of a barge (box-shaped vessel) called closed-form expressions, see Jensen et al. [17], with the same main parameters as the actual vessel are used in the estimation procedure. The main reason for this is to make the procedure as simple as possible, so it can be used for vessels where the detailed hull geometry is unknown. If the actual RAOs of the vessel are pre-calculated by advanced computational tools, e.g., by panel codes or strip theory, the approach will just require interpolation in a hyper-dimensional matrix, which is done in other sea state estimation algorithms. The sea state estimation algorithm is demonstrated on the heave, roll and pitch response measurements of the NTNU-owned and operated research vessel $(\mathrm{R} / \mathrm{V})$ Gunnerus during $\mathrm{DP}$ tests in three different sea states with head, bow, beam, quartering and following sea waves.

The paper is organized as follows: An introduction to wave spectra, response spectra, cross spectra and closed-form expressions is given in Section 2, and Section 3 presents the sea state estimation algorithm. In Section 4 the collection and validation of the response measurements, wave elevation measurements, and tuning of the closed-form expressions is 
discussed, before the estimation results are presented. Section 5 concludes the paper.

\section{Ocean waves and vessel modeling}

\subsection{Sea states}

In small to relatively high sea states, linear theory is often sufficient to describe irregular waves, see Faltinsen [18]. The sea surface elevation for long-crested waves can be described as a finite sum of a large number of sinusoidal wave components with different amplitudes $a_{j}$, wave numbers $k_{j}$, frequencies $\omega_{j}$, phases $\epsilon_{j}$,

$$
\zeta=\sum_{j=1}^{N} a_{j} \sin \left(\omega_{j} t-k_{j} x+\epsilon_{j}\right),
$$

where $t$ is the time, and the wave propagates with (main) propagation direction $\Theta$, as defined in Figure 1a. The wave propagation direction is usually described by a mean direction and a spread. The wave direction relative to the vessel heading is $\beta$, with $\beta=180^{\circ}$ being head sea, and $\beta=0^{\circ}$ being following sea, see Figure $1 \mathrm{~b}$.

The energy distribution of wave frequencies in a long-crested sea state is often described using a wave spectra $S(\omega)$. The energy $E$ can be expressed as

$$
\frac{E}{\rho g}=\frac{1}{2} \zeta_{a}^{2}=\int_{0}^{\infty} S(\omega) d \omega
$$

where $\rho$ is the water density, $g$ is the acceleration due to gravity, and $\zeta_{a}$ is the total wave amplitude. When $N \rightarrow \infty$ and $\Delta \omega \rightarrow 0$, then the sum can be expressed as an integral. Waves are generated when the wind blows on the sea surface, and the wind speed, fetch length (stretch of water that the wind blows over), duration of the wind, water depth, etc. determine what shape the wave spectrum has, see Figure 2 where examples of three wave spectra are shown. The JONSWAP and Pierson-Moskowitz spectra are single peaked describing developing and fully developed sea states, respectively. The Torsethaugen spectrum is double peaked, describing sea states with swell and wind-generated sea. Swell are large waves that have been generated during a storm far away, and typically swell and wind-generated waves may travel in different directions. In some cases, wave spectra without distinct peaks are 


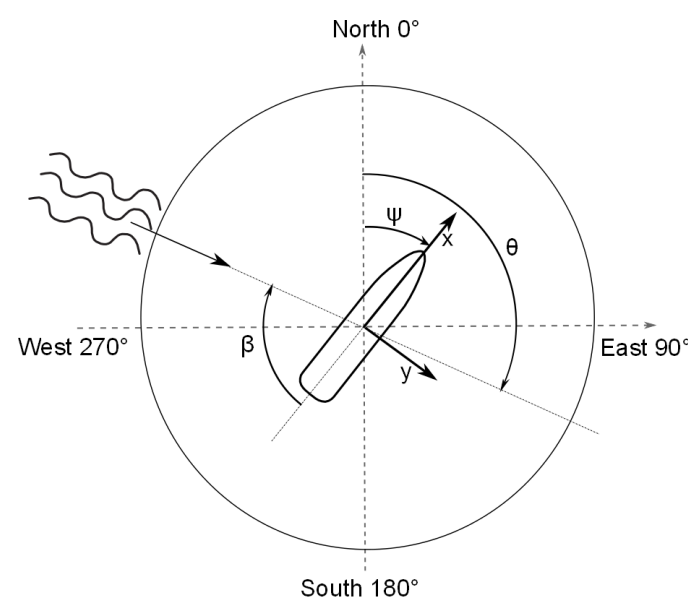

(a) Global wave propagation direction $\Theta$

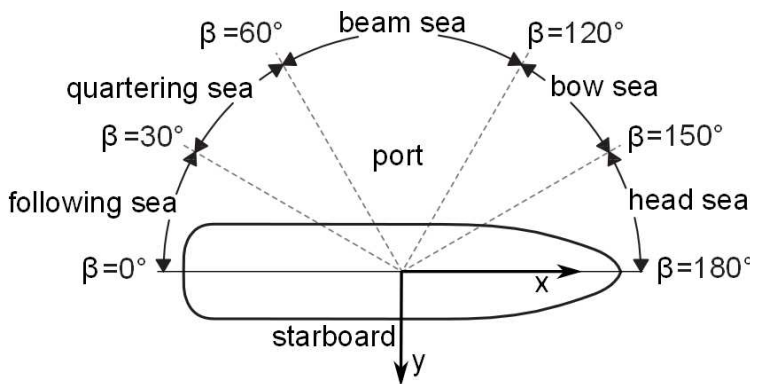

(b) Relative wave direction $\beta$

Figure 1: Definition of the wave propagation direction $\Theta$, heading of the vessel $\psi$, and relative wave direction $\beta$. Starboard incident waves have $\beta \in(-180,0]^{\circ}$, and port incident waves have $\beta \in[0,180]^{\circ}$. The coordinate system $\mathrm{x}$-y represents the body-frame with the z-axis pointing down (into the page), and the dashed coordinate frame in (a) is the North-East-Down (NED)-frame, also with the down-axis pointing downward (into the page). Notice that the vessel is symmetric about the x-axis.

measured. These are not described by the spectra above, but the frequency ranges where the most wave energy is present is still important for marine operations. For instance, in DP, knowing which wave frequency bands contain the most energy is more important than tracking one peak frequency perfectly. The sea state changes in the order of hours, so having reliable estimates is more important than having frequent updates.

In this paper, fully developed wind-generated sea states are considered. It is also assumed that the sea state is stationary in the statistical sense (statistical properties are constant), and that the waves are long-crested. Statistical properties like the significant wave height $H_{s}$ (the mean of the $1 / 3$ highest waves, also denoted $H_{1 / 3}$ ), characteristic periods, like the mean or peak period $T_{p}$ relate to $S(\omega)$ through

$$
\begin{array}{rlrl}
H_{s} & :=4 \sqrt{m_{0}}, & m_{0}:=\int_{0}^{\infty} S(\omega) d \omega, \\
T_{p}:=\frac{2 \pi}{\omega_{p}}, & \omega_{p}:=\underset{j}{\arg \max } S\left(\omega_{j}\right) .
\end{array}
$$

For a measurement time series of the surface elevation, the wave spectrum can be estimated 


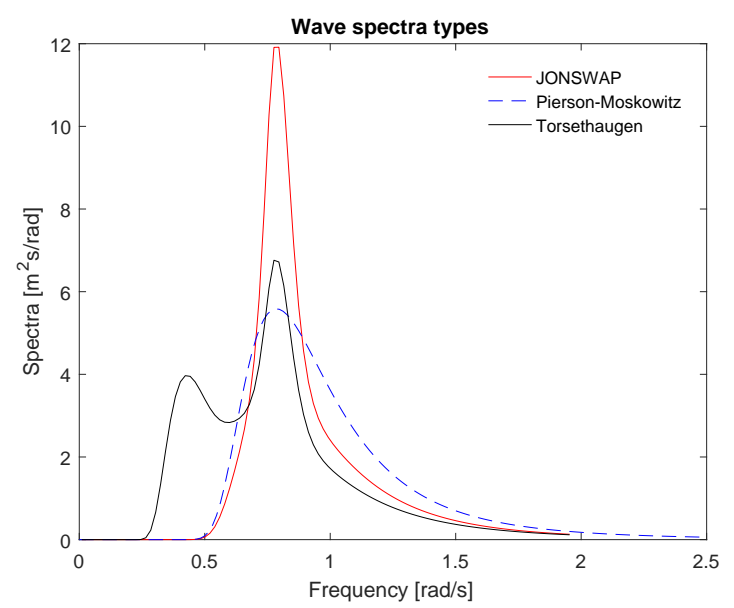

Figure 2: Examples of JONSWAP, Pierson-Moskowitz and Torsethaugen spectra. The wind-generated peak has $H_{s}=7 \mathrm{~m}$ and $T_{p}=8 \mathrm{~s}$ for all spectra, and the swell peak in the Torsethaugen spectrum has $H_{s}=8 \mathrm{~m}$ and $T_{p}=15 \mathrm{~s}$.

by the real part of the Fourier transform of the measurement [18].

\subsection{Vessel response in irregular waves}

For control design purposes, the vessel motion is usually modeled as a mass-damperrestoring system subject to forces from current, wind, and waves. For ships in DP the thrusters will produce mean and slowly varying generalized forces in the horizontal plane to cancel those from the environment. Therefore the control system influences the surge, sway and yaw motion of ships, and the heave $(z)$, roll $(\phi)$ and pitch $(\theta)$ motions are more suited for sea state estimation. The measurements of heave, roll and pitch are recorded in the body-frame, which is defined with positive $\mathrm{x}$-axis pointing towards the bow, positive $\mathrm{y}$-axis pointing towards starboard, and with positive z-axis pointing down, see Figure 1b. In DP the vessel has zero forward speed, and the frequency of encounter is the same as the incident wave frequency.

The relationship between the wave amplitude and the vessel response amplitude (here only heave, roll and pitch are considered) is given by the complex-valued motion RAOs $X_{i}(\omega, \beta)$, which can be calculated using hydrodynamic programs. The relationship is:

$$
R_{i j}(\omega)=X_{i}(\omega, \beta) \overline{X_{j}(\omega, \beta)} S(\omega),
$$



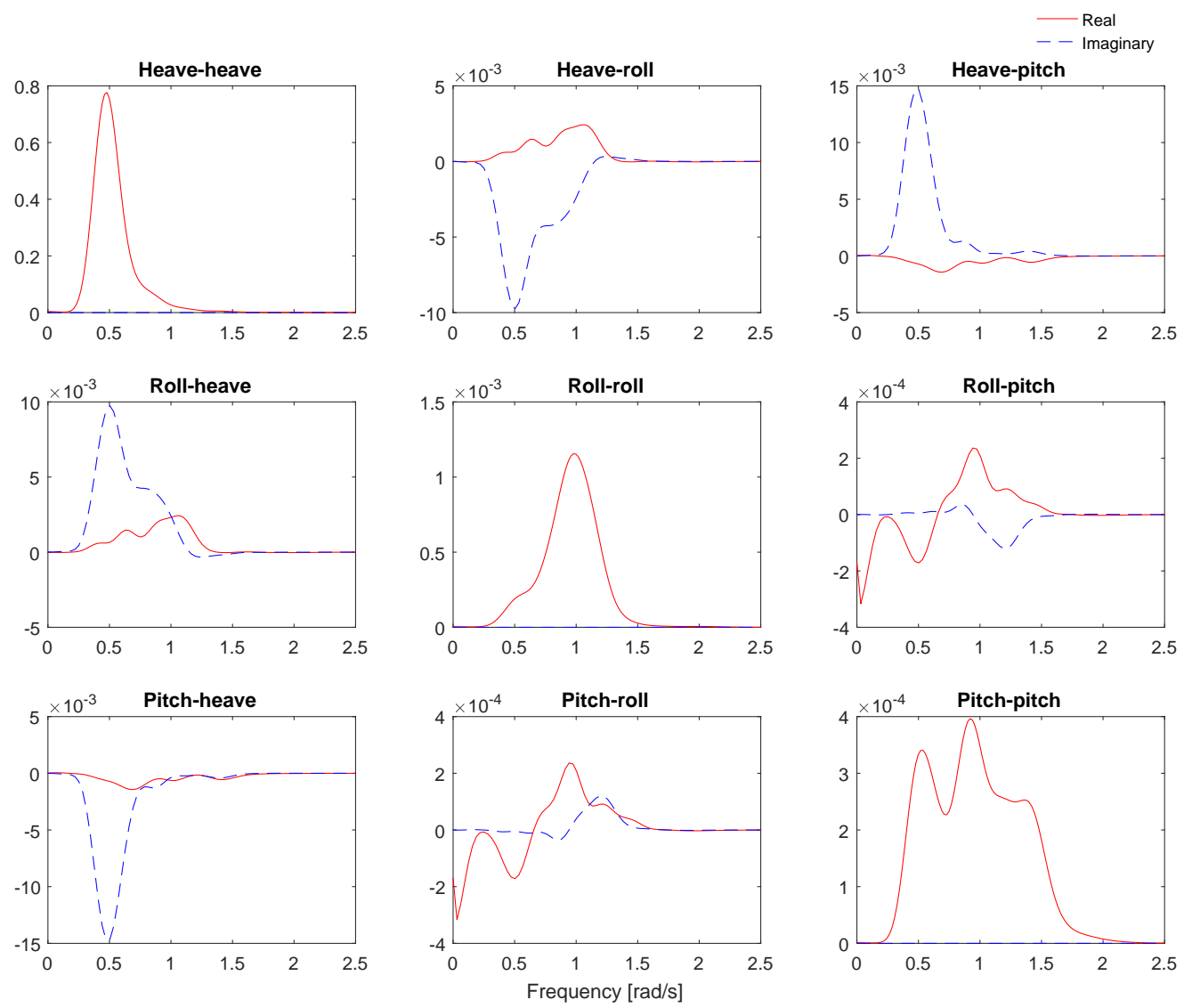

Figure 3: Cross spectra $R_{i j}$ calculated from measured responses in heave, roll and pitch for the data set from Run 3, head seas (see Tables 2 and 3). Frequency [rad/s] on all x-axes.

where $R_{i j}(\omega)$ is the complex-valued cross spectra for the heave, roll, and pitch responses $i, j=\{z, \phi, \theta\}, \overline{X_{j}(\omega, \beta)}$ is the complex conjugate of the RAOs in heave, roll and pitch for relative wave direction $\beta$, and $S(\omega)$ is the wave spectrum. When $i=j, X_{i}(\omega, \beta) \overline{X_{i}(\omega, \beta)}=$ $\left|X_{i}(\omega, \beta)\right|^{2}$, which is the amplitude of the RAO squared. The cross spectra $R_{i j}(\omega)$ calculated from measured responses for a data set from Run 3 are shown in Figure 3 . When $i \neq j, R_{i j}(\omega)$ is complex-valued, and when $i=j$ the imaginary part is zero, $\mathcal{I} m\left(R_{i i}\right)=0$. The imaginary parts of the cross spectra pairs have opposite signs, i.e., $\mathcal{I} m\left(R_{i j}\right)<0 \Leftrightarrow \mathcal{I} m\left(R_{j i}\right)>0$, that are dependent on the incident wave direction. This is used later to determine $\beta$.

The vessel will act as a low-pass filter such that small wave length $\lambda$ compared to the ship length will hardly result in any response. Hence, no information about the waves can 
be obtained from the vessel motion measurements in these cases ${ }^{1}$. Due to the low-pass characteristics the algorithm will work best for wave length larger than a certain value compared to the ship length and breadth. The procedure implicitly assumes that the waveinduced motions are small so that linear theory is applicable, and that the vessel response is in steady state, though the stationary assumption may be relaxed, see for instance [11].

\subsection{Closed-form expressions}

In order to calculate the motion RAOs, $X_{i}(\omega, \beta)$, from the wave amplitude to the response amplitude, of a marine vessel, generally a detailed description of the vessel hull geometry, weight distribution, draught and trim is required for standard as well as advanced computational tools, e.g., the 3D panel code WAMIT, or the 2D strip theory code ShipX. In these tools, the motion RAOs are calculated for a pre-specified set of headings, loading conditions and vessel forward speeds (though here only zero forward speed is considered). Jensen et al. [17] present simplified expressions, called closed-form expressions, for the heave, roll and pitch motions of a homogeneously loaded box-shaped vessel with dimensions $L \times B \times T$ (length, breadth, draught), which approximate the RAOs of a ship. The main reasons for using the closed-form expressions in this procedure, instead of the actual RAOs of the ship, are:

- To demonstrate that it is possible to obtain a sea state estimate including significant wave height, a characteristic period and direction by using limited knowledge of the vessel hull geometry.

- The use of closed-form expressions offer a convenient way to deal with RAOs in varying operational conditions without the need to interpolate.

The RAOs, obtained e.g., by WAMIT, of the real hull geometry, could easily be applied in the sea state estimation algorithm instead.

\footnotetext{
${ }^{1}$ Some studies look at the possibility to infer knowledge about higher frequency wave components by considering the relative motion of the vessel. In theory, this allows methods like the wave buoy analogy to estimate waves of smaller wave length as well, see e.g., Nielsen [19, 20]
} 
The closed-form expressions for heave and pitch in Jensen et al. [17] are derived based on the decoupled heave and pitch dynamics of the vessel. This leads to a semi-analytical expression for the motion RAOs with inputs $L, B, T$, block coefficient $C_{B}$, and ship forward speed $V$ (although $V$ is set to zero here). For roll, the closed-form expression requires the displacement $\Delta$, water-plane area coefficient $C_{W P}$, transverse metacentric height $G M_{T}$, and roll natural period $T_{4 n}$ as additional input. The parameters $G M_{T}$ and $\Delta$ are calculated by ballast programs onboard vessels, usually before the vessel leaves port, in order to ensure sufficient stability of the vessel and avoid capsize. $C_{W P}$ and $C_{B}$ can be approximated for different hull shapes, and the roll natural period may be approximated by

$$
T_{4 n}=\frac{2 \pi}{\omega_{4 n}}, \quad \omega_{4 n}=\frac{\sqrt{g G M_{T}}}{r_{x}}
$$

where $g$ is the acceleration due to gravity, and the roll radius of gyration is $r_{x}=0.4 B$, see Papanikolaou et al. [21].

The roll damping is important to estimate correctly, and is approximated by a linear wave-induced part, and a viscous part. In [17], the linear wave-induced damping is calculated by using two boxes that are rigidly joined, however, here only one box with dimensions $L \times B \times T$ yielded better results. The sectional damping coefficient is determined by an approximation based on the ratio $B / T$ for a wedge-shaped hull, and then multiplied with the length $L$ of the hull. Viscous roll damping is approximated by a factor $0<\mu \ll 1$ of the critical damping $B_{44}^{*}=\frac{T_{4 n} C_{44}}{\pi}$, where $C_{44}=g \Delta G M_{T}$ is the roll restoring coefficient. The viscous damping is highly nonlinear, but linearized approximations based on the critical damping are often used both in simplified approaches, and in panel and strip theory codes.

The closed-form expressions in heave, roll and pitch are in the rest of the paper referred to by $\Phi_{i}(\omega, \beta), i=\{z, \phi, \theta\}$. As a final remark it should be noted that the closed-form RAOs derived by Jensen et al. [17] are, indeed, closed-form formulas, calculable/obtainable with a simple calculator at hand. This property makes the work [17] particularly useful for the present study, as addressed by the bullet points above. However, in addition to [17], the reader may also want to consult some of the more general studies about (highly) simplistic models for ship motions; see for instance Blagoveshchensky [22], Gerritsman and Beukelman 
[23], Bhattacharyya [24], to name a few.

\section{Sea state estimation algorithm}

The sea state estimate, consisting of mean wave direction and a wave spectrum estimate, is computed in two steps, which are described in detail subsequently, but summarized as follows: Firstly, the response spectra in heave, roll and pitch, when $i=j R_{i i}(\omega)$, and the closed-form expressions are used to find an initial estimate of the unknown wave spectrum $S(\omega)$. This is done by solving the following equation through iteration

$$
R_{i i}(\omega)=\left|\Phi_{i}(\omega, \beta)\right|^{2} S(\omega)
$$

which is the relation between the sea state and the vessel response in Eq. (4) when $i=j$, with the RAOs substituted with the closed-form expressions from Section 2.3, $i=\{z, \phi, \theta\}$. $R_{i i}(\omega)$ is the real part of the Fourier transformation of the measured heave, roll and pitch vessel response, respectively.

Secondly, the imaginary parts of the cross spectra $R_{i j}(\omega), i \neq j$ are used to estimate

the relative wave direction $\hat{\beta}$, and then the estimates of the peak wave period $\hat{T}_{p}:=\frac{2 \pi}{\hat{\omega}_{p}}$ and significant wave height $\hat{H}_{s}$ are computed.

\subsection{Wave spectrum estimate}

The method does not assume a wave spectrum shape, or parametrize it in any way. Instead, the sea state estimate is based on the direct solution of the linear equation, Eq. (6), that is solved using an iterative scheme, as follows

$$
\begin{aligned}
\tilde{R}_{i i} & =R_{i i}(\omega)-\hat{R}_{i i} \\
\hat{S}_{i}(k) & =\hat{S}_{i}(k)+h \tilde{R}_{i i} \\
\hat{R}_{i i} & =\left|\Phi_{i}(\omega, k)\right|^{2} \hat{S}_{i}(k) .
\end{aligned}
$$

The implemetation is given in Algorithm 1, and is explained in detail below.

- Discretize the directions and the frequencies into $N_{\beta}$ and $N_{\omega}$ parts. Since the wave direction is unknown initially, a loop is made over all directions $N_{\beta}$. 
- Initialize the estimate of the wave spectrum, and the estimate of the response spectrum to zero, $\hat{S}_{i}=0$ and $\hat{R}_{i i}=0$. Compute the difference between the measured response spectrum from Section 2.2 and the estimated response spectrum $\tilde{R}_{i i}=R_{i i}(\omega)-\hat{R}_{i i}$.

- Use $\tilde{R}_{i i}$ to make adjustments to $\hat{S}_{i}$ with step size $h>0$, and calculate the response spectrum estimate $\hat{R}_{i i}$ again. Do this until a threshold is reached $\left|\tilde{R}_{i i}\right| \leq \epsilon$, for $\epsilon>0$.

- Since the RAOs of a box-shaped vessel are applied, the values for pitch beam seas and for roll in head and following seas are zero $\Phi_{i}(\omega, \beta)=0$. The iteration is terminated in these cases, giving a wave spectrum estimate of zero, $\hat{S}_{i}(k)=0$.

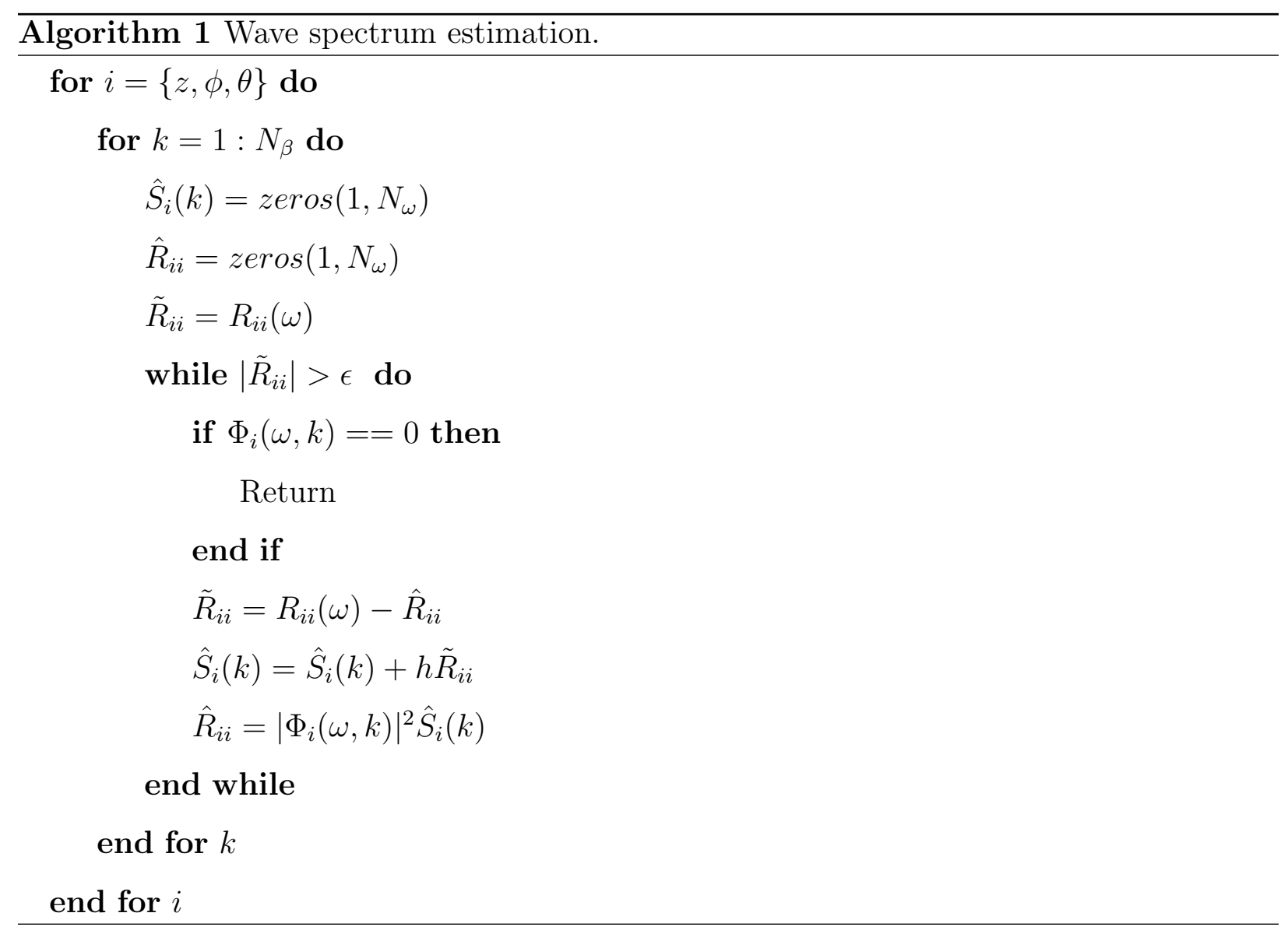


The output from Algorithm 1 are three wave spectrum estimates per direction, yielding a spectrum estimate matrix of dimension $3 \times N_{\beta} \times N_{\omega}$,

$$
\bar{S}=\left[\begin{array}{cccc}
\hat{S}_{z}(1) & \hat{S}_{z}(2) & \ldots & \hat{S}_{z}\left(N_{\beta}\right) \\
\hat{S}_{\phi}(1) & \hat{S}_{\phi}(2) & \ldots & \hat{S}_{\phi}\left(N_{\beta}\right) \\
\hat{S}_{\theta}(1) & \hat{S}_{\theta}(2) & \ldots & \hat{S}_{\theta}\left(N_{\beta}\right)
\end{array}\right]
$$

Now it remains in this former part to compute the peak frequency, $\omega_{i}(k)$, and significant wave height $H_{i}(k), i=\{z, \phi, \theta\}, k=\left\{1, \ldots, N_{\beta}\right\}$, see Eq. (3), for each of the wave spectra in $\bar{S}$, Eq. (8). The result is collected in two matrices with dimensions $3 \times N_{\beta}$.

$$
\begin{aligned}
\bar{H}_{s}= & {\left[\begin{array}{llll}
H_{z}(1) & H_{z}(2) & \ldots & H_{z}\left(N_{\beta}\right) \\
H_{\phi}(1) & H_{\phi}(2) & \ldots & H_{\phi}\left(N_{\beta}\right) \\
H_{\theta}(1) & H_{\theta}(2) & \ldots & H_{\theta}\left(N_{\beta}\right)
\end{array}\right] } \\
\bar{\omega}_{p} & =\left[\begin{array}{llll}
\omega_{z}(1) & \omega_{z}(2) & \ldots & \omega_{z}\left(N_{\beta}\right) \\
\omega_{\phi}(1) & \omega_{\phi}(2) & \ldots & \omega_{\phi}\left(N_{\beta}\right) \\
\omega_{\theta}(1) & \omega_{\theta}(2) & \ldots & \omega_{\theta}\left(N_{\beta}\right)
\end{array}\right]
\end{aligned}
$$

Algorithm 1 is a set of $3 \times N_{\beta}$ linear equations that are computationally efficient to solve. In this paper we have used $N_{\beta}=19$ directions, $\beta=\{0,10, \ldots, 180\}$, and $N_{\omega}=300$. In the following it is explained how to make the selection of the relative wave direction estimate, considering also the interval $\beta=(-180,0]$.

\subsection{Wave direction estimate}

The relative wave direction estimate is found in two stages. The initial direction DirID is found by using the significant wave height matrix $\bar{H}_{s}$ in Eq. (9), and this information is coupled with the imaginary parts of the cross spectra in heave-roll and heave-pitch. The approach for selecting the wave direction is explained in the following.

Stage 1: An initial relative wave direction estimate can be made as either head/following, bow/quartering, or beam seas. In Figure 4 the significant wave heights from the matrix in Eq. (9) are plotted for the same sea state (Run 3, see Table 3 in Section 4). The vessel is in head seas in (a) and beam seas in (b). The measured significant wave height and correct 


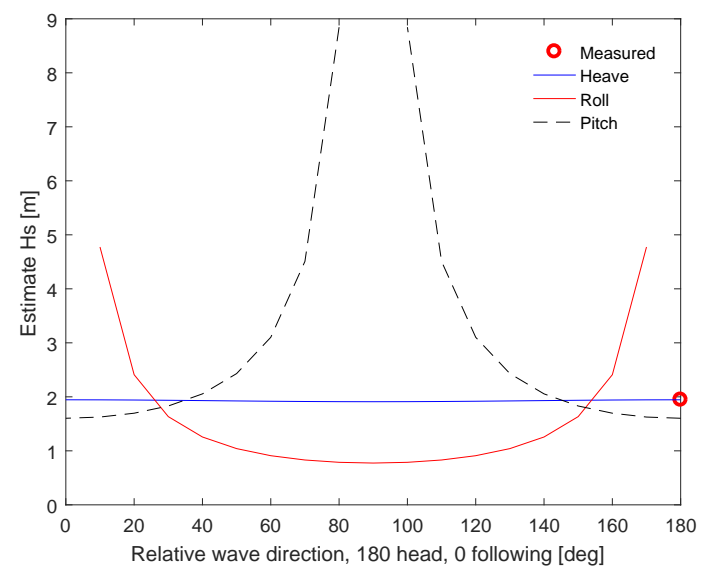

(a) Head sea

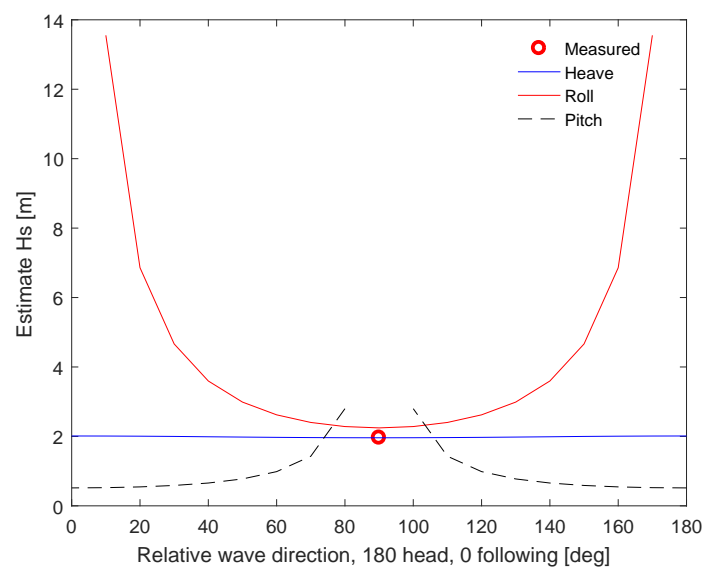

(b) Beam sea

Figure 4: Significant wave height in Eq. (9) plotted against relative wave direction. This data set is from Run 3, for actual vessel heading head in (a) and beam in (b), see Tables 2 and 3 for details. The measured significant wave height and correct relative direction are indicated by the red circles.

relative direction are indicated by the red circle in both plots. The wave height estimates $H_{\phi}(\beta=0), H_{\phi}(\beta=180)$ and $H_{\theta}(\beta=90)$ are not included in the plots, as they are set to zero in Algorithm 1. The figures are symmetric since the closed-form expressions are used instead of the RAOs of the ship.

The estimated significant wave heights from using the heave response and heave closedform expression vary little over the direction, and are close to the measured $H_{s}$, see the red dots in Figures 4. This is used as the base case for determining the incident direction of the waves. Since the closed-form expressions for roll and pitch vary a lot over direction, the $H_{\phi}$ and $H_{\theta}$ also vary a lot with direction. The angle $\beta$ where the $\bar{H}_{s}$ are closest, is chosen as the initial direction DirID. Based on this idea, Algorithm 2 identifies if the waves are head/following, bow/quartering, or beam sea, and is explained further below. $\delta_{H}>0$ and $\delta_{\max H}>0$ are chosen as factors of $\frac{1}{N_{\beta}} \sum_{j=1}^{N_{\beta}} H_{z}(j)$ from Eq. (9).

- When the sea state is bow or quartering, the maximum $H_{\theta}$ and $H_{\phi}$ are about the same order of magnitude.

- When the significant wave height from using pitch for head (or following) $H_{\theta}(\beta=180$ ) 


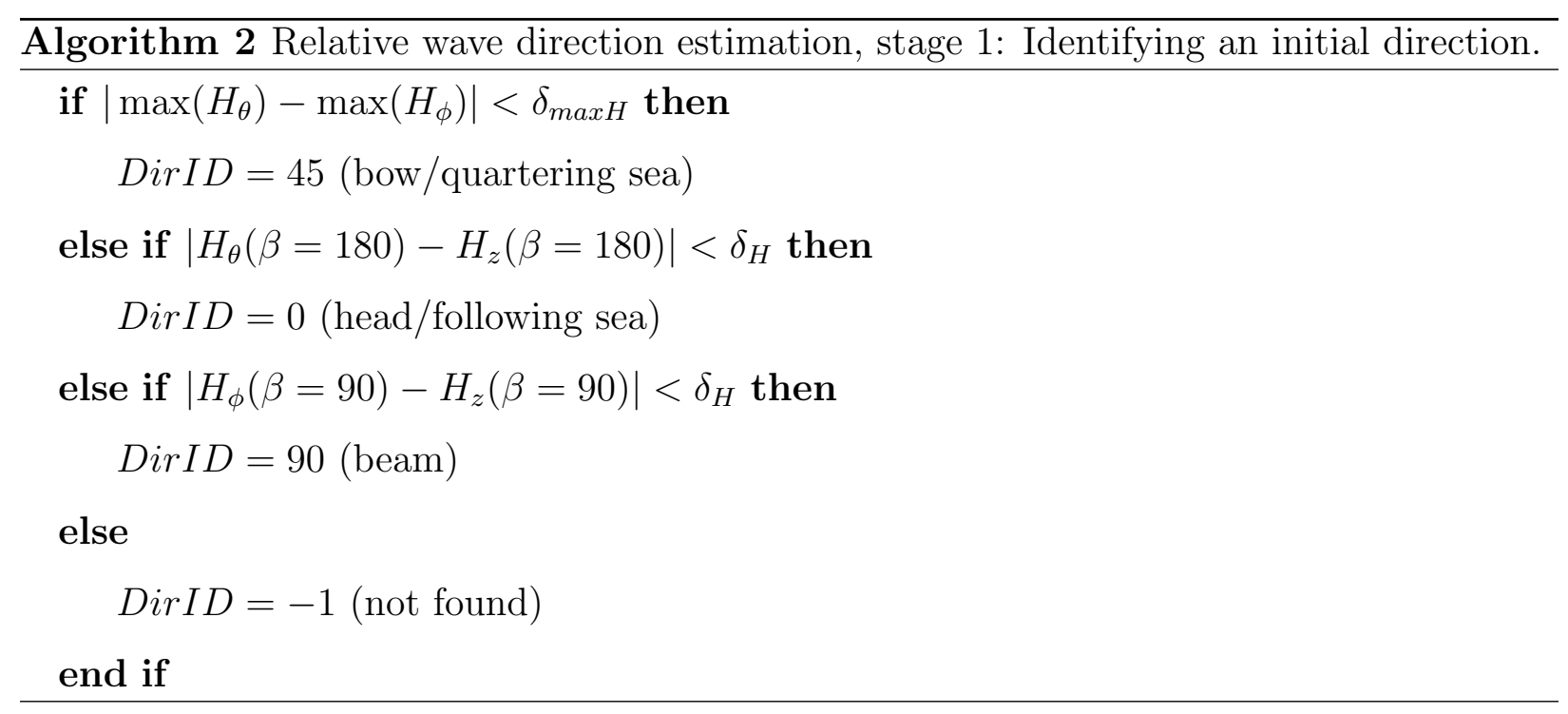

sea is close to the significant wave height estimate from heave for head (or following) sea $H_{z}(\beta=180)$, the direction is either head or following. From Figure 4a it is ruled out that the waves are approaching from the side, since then $H_{\theta}(\beta=80)$ and $H_{\theta}(\beta=100)$ are a lot larger than $H_{z}$ for the same directions.

- When the significant wave height using roll in beam sea $H_{\phi}(\beta=90)$ and using heave $H_{z}(\beta=90)$ are close, the sea state is beam sea. In Figure $4 \mathrm{~b} H_{\phi}$ for $\beta=10^{\circ}$ and $\beta=170^{\circ}$ is significantly larger than $H_{z}$ for the same directions, which rules out that the waves are head or following.

Stage 2: The next step is to calculate the direction estimate $\hat{\beta}$ by using the initial direction DirID from Algorithm 2, and the imaginary parts of the heave-pitch and heaveroll cross spectra $\mathcal{I} m\left(R_{z \phi}\right)$, and $\mathcal{I} m\left(R_{z \theta}\right)$, see Algorithm 3. The heave response is symmetric about the $\mathrm{x}$-axis (body-frame), and the pitch response is anti-symmetric about the $\mathrm{y}$-axis, see Figure 5 for an illustration. The symmetric and anti-symmetric properties of the responses, are reflected in the imaginary part of the heave-pitch cross spectra $\mathcal{I} m\left(R_{z \theta}\right)$, which has opposite sign for head and following sea, see the first if-statement $\operatorname{Dir} I D==0$ of Algorithm 
3. The 'peak' function in Algorithm 3 is defined as

$$
\begin{aligned}
\operatorname{peak}\left(\mathcal{I} m\left(R_{i i}\right)\right) & :=\left\{\mathcal{I} m\left(R_{i i}\left(\omega_{J}\right)\right):\right. \\
\omega_{J} & \left.=\underset{j}{\arg \max }\left|\mathcal{I} m\left(R_{i i}\left(\omega_{j}\right)\right)\right|, i=\{z, \phi, \theta\}\right\},
\end{aligned}
$$

corresponding to the largest extreme, either maxima or minima.

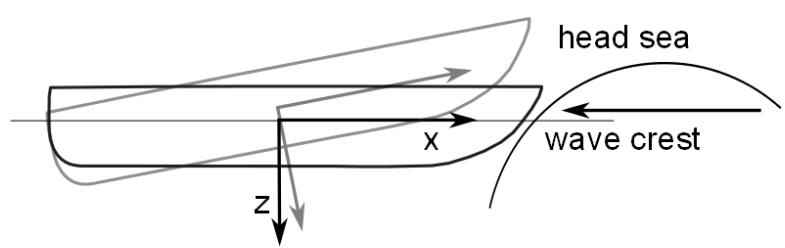

following sea

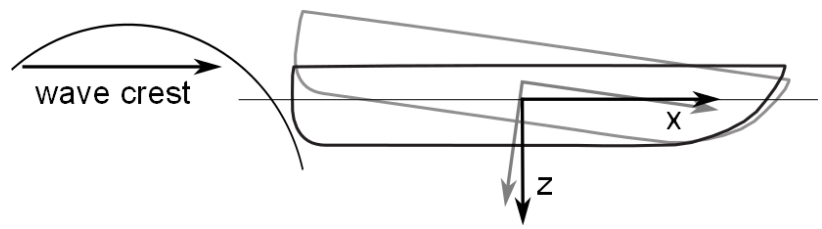

Figure 5: Sketch of the heave and pitch responses to a wave crest for head and following sea for zero forward speed. For head sea, the heave response is upwards, with the bow upwards, and for following sea the heave response is still upwards, but not the bow goes downwards.

For beam seas, $\operatorname{Dir} I D==90$, starboard and port seas can be distinguished by using the imaginary part of the heave-roll (or roll-heave) cross spectra $\mathcal{I} m\left(R_{z \phi}\right)$ in a similar manner. The roll response is anti-symmetric about the body x-axis, giving opposite sign for the roll angle when a wave crest approaches from port and starboard side, and the heave response is symmetric about the x-axis. When $\operatorname{Dir} I D==45$, indicating bow or quartering seas, there are four possibilities for the wave direction, because of zero forward-speed and a box-shaped vessel. Then $\mathcal{I} m\left(R_{z \theta}\right)$ and $\mathcal{I} m\left(R_{z \phi}\right)$ are used in combination, see the elseif-statement for $\operatorname{Dir} I D==45$ in Algorithm 3. If the initial direction estimate was not found, $\hat{\beta}=-1$.

It should be realized that the outlined procedure for the wave direction estimate strictly holds only in case of zero-forward speed and for a sea state described by long-crested waves. Without forward speed, waves that are following, will always be following, since the vessel will not travel faster than the waves, as can happen in some cases with forward speed. The 


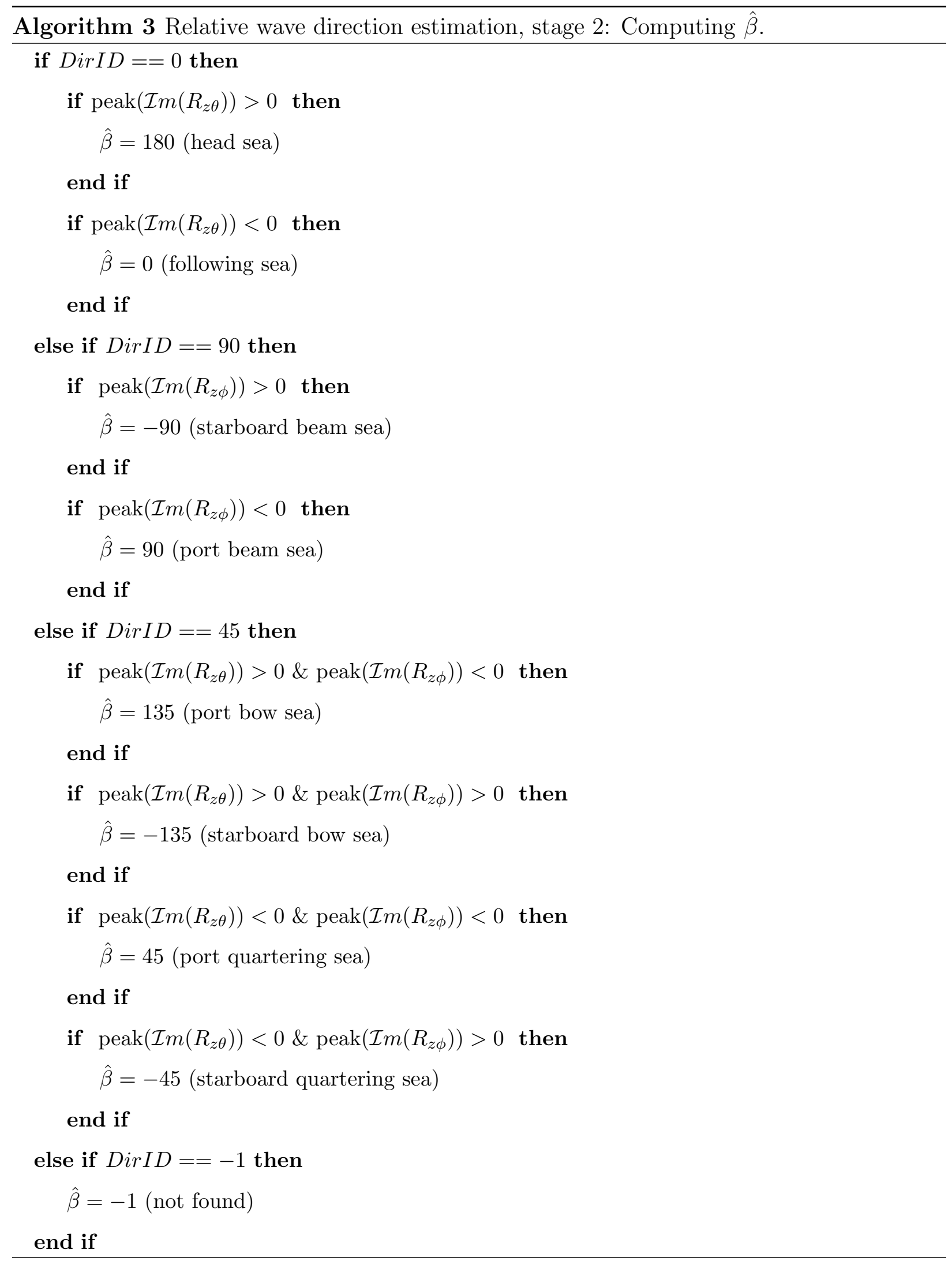


(geographical) wave propagation direction estimate $\hat{\Theta}$ can be computed by using the heading of the vessel, see Figure 1a.

\subsection{Peak frequency and significant wave height estimates}

In Brodtkorb et al. [14], it was found through a series of model-scale experiments at zero forward speed, that the best peak wave frequency estimate was achieved by using the mean of the heave and pitch response peak frequencies. Therefore the mean of the peak frequencies following from the wave spectrum estimate for heave and pitch, for the estimated incident wave direction, are used:

$$
\hat{\omega}_{p}=\frac{\omega_{z}(\hat{\beta})+\omega_{\theta}(\hat{\beta})}{2}
$$

The peak frequencies for the estimated wave spectrum were found to be consistent for all directions, and therefore if the wave direction estimate is not found reliable, a peak frequency estimate may still be obtained as the average of the peak frequencies obtained for all directions in heave and pitch. The peak period estimate is $\hat{T}_{p}=\frac{2 \pi}{\hat{\omega}_{p}}$. In beam seas only the heave estimate us used, since the pitch estimate is set to zero. The peak frequency and significant wave height estimates are summarized in Algorithm 4.

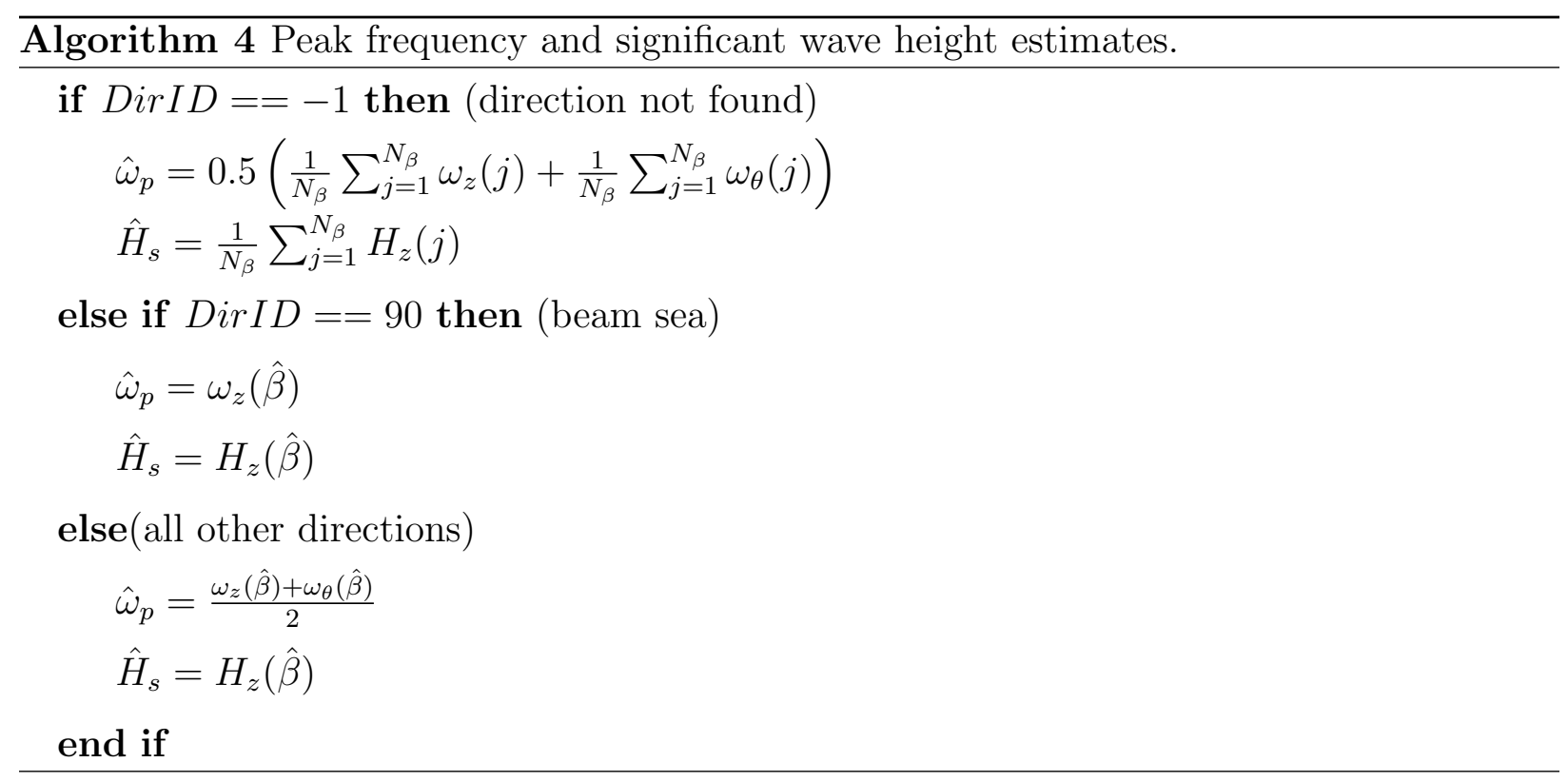


The estimate of the significant wave height in heave is consistent for all directions, see Figure 4, and therefore

$$
\hat{H}_{s}=H_{z}(\hat{\beta})
$$

Again, if the wave direction estimate is not found, the average of the heave significant wave height can be used instead.

\section{Data validation, estimation results and discussion}

In this section the data collection setup is described and the data and closed-form expressions are validated, before the estimation results are presented and discussed.

\subsection{Data collection}

The full-scale DP response measurements were collected during a test campaign in 2013 onboard R/V Gunnerus, see Table 1 for main dimensions. The tests were originally done in order to document the effect of a thruster retrofit, where the main propulsion was changed from two conventional fixed pitch propeller-rudder combinations to two Rolls Royce rimdriven azimuthing thrusters, see Steen et al. [25]. The R/V Gunnerus is a test platform for biologists, archeologists, marine robotics, and recently for DP and autopilot algorithms [26]. Table 2 gives an overview over the test cases in three sea states. In the first sea state response data for head, beam, quartering and following sea were recorded. The second sea state has measurements for bow sea as well. The third sea state only has two relative directions measured, head and beam seas. The relative directions stated here are the intentional relative directions, and are not exactly what was run, since the incident wave direction was judged by sight during the tests. The actual relative directions calculated from the wave buoy direction measurement and the heading of the vessel, are given together with the estimation results in Table 4. The response of the vessel was recorded for 15 minutes in each relative wave direction.

As external information, useful for validation purposes, the sea surface elevation was measured using a directional wave rider buoy that was deployed close to where the DP tests 
Table 1: R/V Gunnerus main parameters used to calculate closed-form expressions.

\begin{tabular}{lr} 
Parameter & Value \\
\hline Length, $L_{p p}$ & $28.9 \mathrm{~m}$ \\
Breadth, $B$ & $9.6 \mathrm{~m}$ \\
Draught, $T$ & $2.7 \mathrm{~m}$ \\
Block coefficient, $C_{B}$ & $0.56[-]$ \\
Waterplane coefficient, $C_{W P}$ & $0.837[-]$ \\
Displacement, $\Delta$ & $417000 \mathrm{~kg}$ \\
Transverse metacentric height, $G M_{T}$ & $2.663 \mathrm{~m}$
\end{tabular}

Table 2: Summary of the test cases for Run 1-3.

\begin{tabular}{lc} 
Run & Relative direction $\beta[\mathrm{deg}]$ \\
\hline 1 & $\{0,45,90,180\}$ \\
$2 / 2^{*}$ & $\{0,45,90,135,180\}$ \\
3 & $\{90,180\}$ \\
\hline
\end{tabular}

took place. The sea states are in the next sections referred to by run numbers defined in Table 3. The statistical values listed in the table are calculated from the post-processed time series from the wave buoy. The wave elevation time series used to calculate the sea state parameters correspond to the time of the DP tests for the three days. The WAFO toolbox [27] for MATLAB ${ }^{\circledR}$ was used to post-process the response and wave measurements.

The sea states in Run 1 and 3 are single-peaked that resemble JONSWAP spectra, and the sea state in Run 2 is double peaked like the Torsethaugen spectrum, with the first values for Run 2 in Table 3 corresponding to wind-generated waves, and the second corresponding to swell. Since the sea state estimation algorithm does not differentiate between multiple peaked spectra at this point, Run 2 is formulated alternatively as Run $2 *$. The significant wave height is calculated as in Eq. (3a), and the peak period, direction and spread are taken as the values for the highest peak, corresponding to the wind-generated waves. The 
alternative formulation $2^{*}$ is used in the discussion of the results. In literature, there exists schemes for partitioning the wave spectra into wind-generated waves and swell, see for instance Montazeri et al. [28].

Table 3: Summary of sea states, with most prominent values for the significant wave height $H_{s}$, peak period $T_{p}$, wave propagation direction $\Theta$, and direction spread, as derived from the wave buoy measurements.

\begin{tabular}{clccc} 
Run & $H_{s}[\mathrm{~m}]$ & $T_{p}[\mathrm{~s}]$ & $\Theta[\mathrm{deg}]$ & Spread $[\mathrm{deg}]$ \\
\hline 1 & 2.27 & 10 & 160 & 34.0 \\
2 & $\{1.1,0.9\}$ & $\{8,13.5\}$ & $\{190.2,72\}$ & $\{5.3,10.2\}$ \\
$2^{*}$ & 1.71 & 8 & 190.2 & 5.3 \\
3 & 1.92 & 15.3 & 72 & 12.4 \\
\hline
\end{tabular}

\subsection{Tuning and validation of closed-form expressions}

In this section the closed-form expressions are compared with the ShipX-calculated motion RAOs for R/V Gunnerus. Figure 6 compares the RAOs calculated using ShipX and the closed-form expressions for the tuning found in this section, for all encounter directions $\beta=\{0,10, \ldots 180\}^{\circ}$. The arrow indicates how the amplitude of the RAOs vary with increasing $\beta$. A note of caution worth mentioning is that ShipX uses strip theory to calculate the RAOs of a vessel. Since $\mathrm{R} / \mathrm{V}$ Gunnerus has $L / B=3$, strip theory is not strictly speaking valid for this vessel, however, it is considered accurate enough for validation of the closed-form expressions.

Starting with the heave and pitch closed-form expressions. In [17] it is recommended that for block coefficient $C_{B}<1$ use $B C_{B}$ as the breadth of the box, so that the buoyancy of the box and the ship are equal. In this case if the length $L=C_{B} L_{p p}$ is used instead, both the heave and pitch closed-form expressions are a lot closer to the ShipX RAOs, and the buoyancy for the ship and the box are still equal. A reason why $L=C_{B} L_{p p}$ works well may be that $\mathrm{R} / \mathrm{V}$ Gunnerus is a relatively short vessel compared to its breadth $L / B=3$, and at the same time it nearly fills a rectangle seen from above, with waterplane area coefficient $C_{W P}=0.837$. 

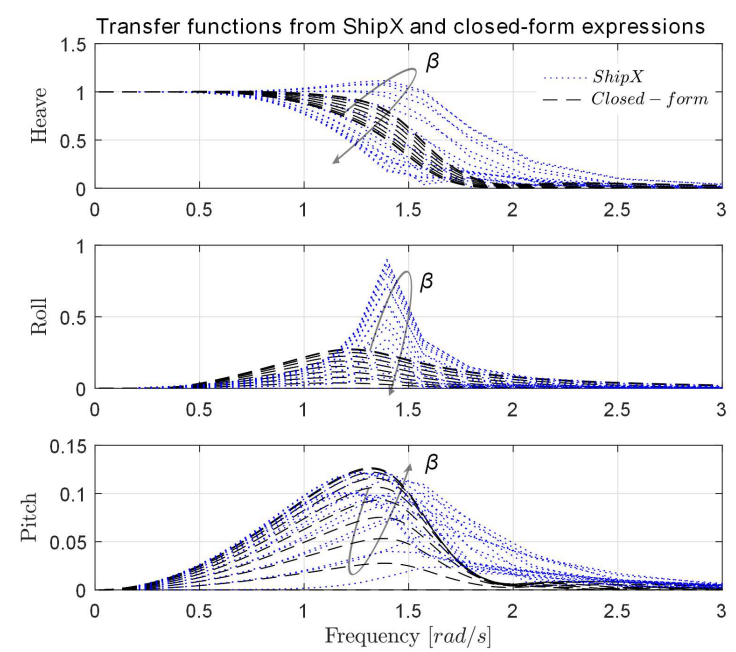

Figure 6: ShipX-calculated motion RAOs and closed-form expressions in heave, roll and and pitch for all directions $\beta$. The arrow indicates how the amplitude varies with increasing $\beta$.

The roll closed-form expression needs some more attention than the others, because in general, roll is a response that is typically susceptible to larger inaccuracies due to effect of nonlinearities in damping and restoring forces. The roll response of the vessel is centred close to the roll natural frequency, with the level of damping deciding how narrow-peaked the RAO is. Therefore the measured roll response in one sea state and one heading is used as a tuning case for the roll closed-form expression. The measured roll RAO can be calculated by solving Eq. (4) with $i=j$ for the RAO, $X_{\phi}^{\text {meas }}(\omega, \beta)$. The measured RAO for Run 2 with $\beta=45^{\circ}$ (quartering sea) is plotted alongside the closed-form expression in roll in Figure 7. The roll damping and peak frequency were tuned to get similar shapes for the closedform expression and the measured RAO. The sectional wave radiation damping coefficient was found using the wedge hull form, see Jensen et al. [17], as the approximations are in the correct $B / T$-range $(B / T$ for Gunnerus is $9.6 / 2.7=3.55)$. Adding viscous damping of $\mu=0.3$ of the critical damping made the closed-form expression in roll similar to the measured RAO. The viscous effects in the ShipX-calculated roll RAO are underestimated, as seen in Figure 6, since the peak is much higher than the roll closed-form expression. The natural frequency in the roll closed-form expression was approximated by Eq. (5) with the $G M_{T}$ given in Table 1 , and the radius of gyration $r_{x}=0.4 B$, as suggested in [21]. 


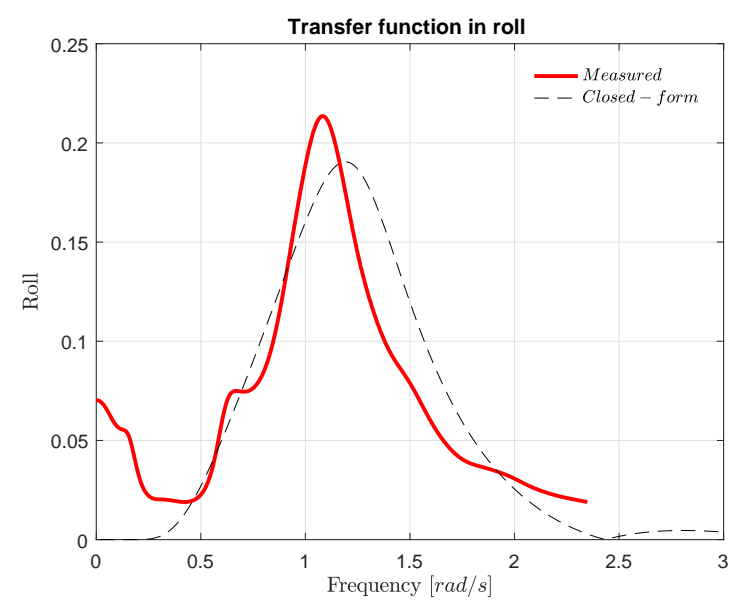

Figure 7: Closed-form expression for roll compared with the measured $\mathrm{RAO}$ for Run $2, \beta=45^{\circ}$ (quartering sea).

\subsection{Data validation}

In this section the data gathered by the wave buoy and RAOs calculated using ShipX are used to validate the closed-form expressions against the measurements of heave, roll and pitch. Notice that this is the reverse process to estimating the sea state, and is only done for validation purposes. The theoretical response is calculated as follows:

$$
\begin{aligned}
R_{i i}^{S h i p X}(\omega) & =\left|X_{i}(\omega, \beta)\right|^{2} S_{\text {buoy }}(\omega) \\
R_{i i}^{C F}(\omega) & =\left|\Phi_{i}(\omega, \beta)\right|^{2} S_{\text {buoy }}(\omega),
\end{aligned}
$$

where $R_{i i}^{S h i p X}$, and $R_{i i}^{C F} i=\{z, \phi, \theta\}$ are the calculated response spectrum in heave, roll and pitch, $X_{i}(\omega, \beta)$ are the real parts of the RAOs calculated using ShipX, $\Phi_{i}(\omega, \beta)$ are the closed-form expressions, and $S_{\text {buoy }}(\omega)$ is the Fourier transform of the wave elevation measured by the wave rider buoy. The direction from the buoy and the heading of the vessel are used to calculate the relative wave direction $\beta$. Figure 8 shows the measured and calculated response in heave, roll and pitch for Run 2 , for $\beta=45^{\circ}$ (quartering sea).

The theoretical $R_{i i}^{S h i p X}$, and $R_{i i}^{C F}$, and measured responses generally correspond well, for heave and pitch. For roll the ShipX RAOs are overestimated (see Figure 7), and therefore the $R_{\phi \phi}^{\text {ShipX }}$ is a lot larger than the others, and is omitted in the plot. The roll closedform expression performs adequately. It is observed that for beam seas the measured pitch 

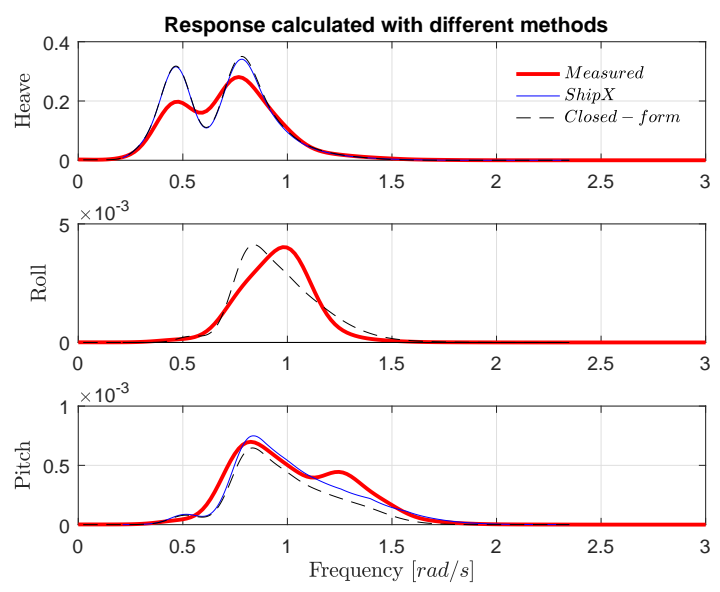

Figure 8: Measured and calculated response spectra using ShipX calculated RAOs and using the closed-form expressions in Section 2.3. The waves used are Run 2 for $45^{\circ}$ (quartering sea).

response is generally larger than the theoretical $R_{i i}^{C F}$, and the same goes for the roll response for close to head and following seas. One reason for this might be that the waves were not completely long-crested since the wave propagation direction had a spread, and waves with different directions than the mean wave direction excite the vessel response.

\subsection{Estimation results}

The procedure described in Section 3 was applied to all the response measurements available, see Table 2. Figures 9-11 show the estimated wave spectra using the heave and pitch responses for all response time series in each sea state. A summary of the estimated sea state parameters $\hat{H}_{s}, \hat{T}_{p}$ and $\hat{\beta}$ and the estimation errors are shown in Table 4 . The estimation errors are calculated as

$$
\begin{aligned}
\tilde{\beta} & =|\beta-\hat{\beta}|\left[^{\circ}\right] \\
\tilde{H}_{s} & =100 \frac{\left|H_{s}-\hat{H}_{s}\right|}{H_{s}}[\%] \\
\tilde{T}_{p} & =100 \frac{\left|T_{p}-\hat{T}_{p}\right|}{T_{p}}[\%],
\end{aligned}
$$

with $\beta, H_{s}$ and $T_{p}$ calculated from the wave buoy measurements, see Table 3 . Note that the pitch response is zero for beam seas, so no sea state estimate from pitch is obtained for 


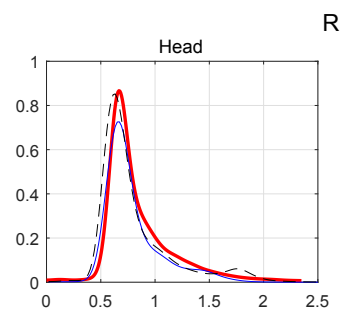

Run 1
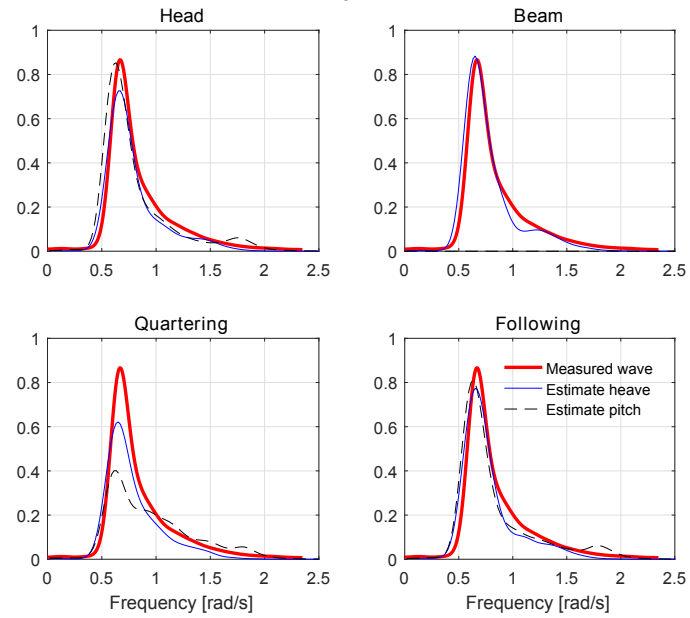

Figure 9: Measured and estimated wave spectra $\left[\mathrm{m}^{2} \mathrm{~s} / \mathrm{rad}\right]$ using the heave and pitch response for the sea state in Run 1.

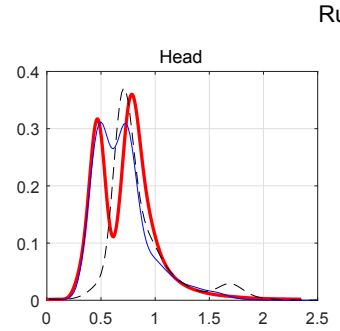

Run 2
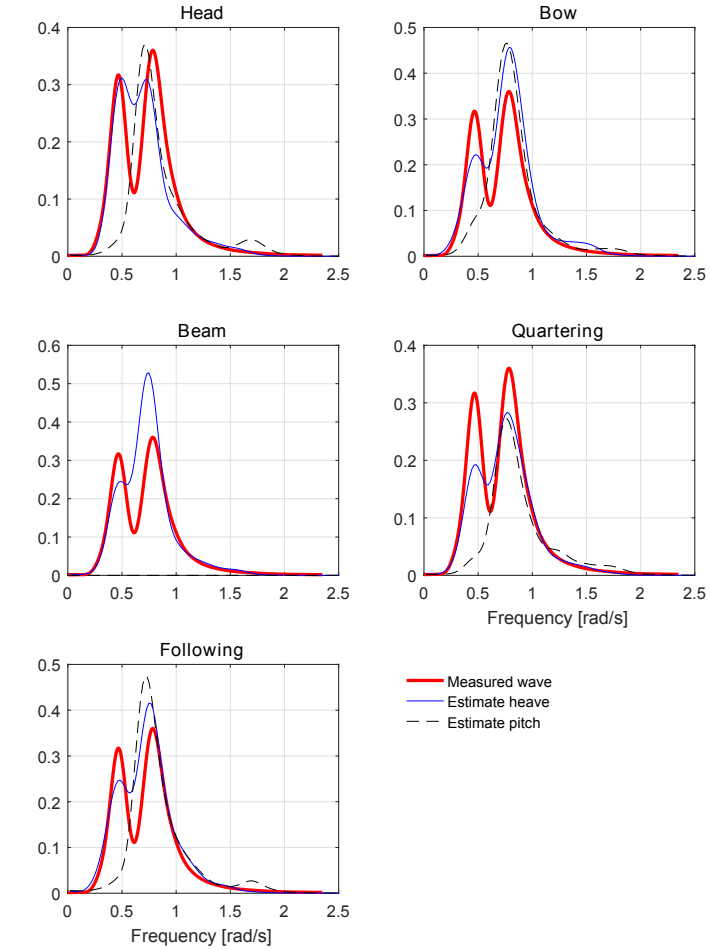

Figure 10: Measured and estimated wave spectra $\left[\mathrm{m}^{2} \mathrm{~s} / \mathrm{rad}\right]$ using the heave and pitch response for the sea state in Run 2. 

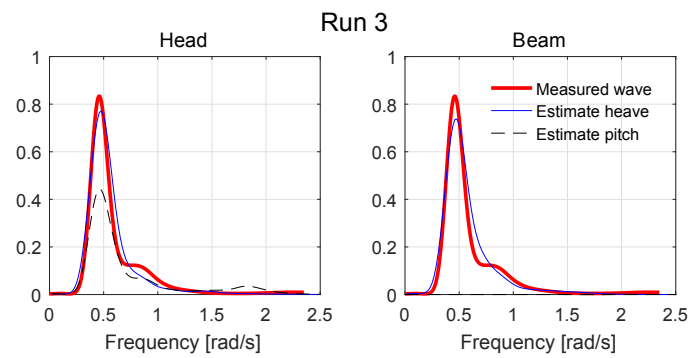

Figure 11: Measured and estimated wave spectra $\left[\mathrm{m}^{2} \mathrm{~s} / \mathrm{rad}\right]$ using the heave and pitch response for the sea state in Run 3.

Table 4: Measured wave parameters using a directional wave rider buoy, estimated parameters using Algorithms 1-4, and the estimation error calculated by Eq. (16)

\begin{tabular}{clccc|ccc|ccc} 
& & \multicolumn{4}{c}{ Measurements } & \multicolumn{3}{c}{ Estimates } & \multicolumn{3}{c}{ Estimation errors } \\
Run & Heading & $\beta[\mathrm{deg}]$ & $H_{s}[\mathrm{~m}]$ & $T_{p}[\mathrm{~s}]$ & $\hat{\beta}[\mathrm{deg}]$ & $\hat{H}_{s}[\mathrm{~m}]$ & $\hat{T}_{p}[\mathrm{~s}]$ & $\tilde{\beta}[\mathrm{deg}]$ & $\tilde{H}_{s} \%$ & $\tilde{T}_{p} \%$ \\
\hline 1 & head & -175.6 & 2.27 & 10 & -180 & 2.1044 & 9.638 & 4.39 & 7.56 & 3.617 \\
1 & beam & 95.1 & 2.27 & 10 & 90 & 2.26 & 9.638 & 5.1 & 0.725 & 3.167 \\
1 & quartering & 50 & 2.27 & 10 & 45 & 1.999 & 9.781 & 5 & 12.16 & 2.192 \\
1 & following & 4.3 & 2.27 & 10 & 0 & 2.161 & 9.781 & 4.3 & 5.08 & 2.192 \\
& & & & & & & & & & \\
$2^{*}$ & head & 179 & 1.71 & 8 & 180 & 1.6747 & 10.48 & 1 & 1.846 & 30.03 \\
$2^{*}$ & bow & 134.8 & 1.71 & 8 & 135 & 1.8724 & 8.091 & 0.2 & 9.779 & 1.133 \\
$2^{*}$ & beam & 89.2 & 1.71 & 8 & 90 & 1.8708 & 8.402 & 0.8 & 9.685 & 5.02 \\
$2^{*}$ & quartering & 44.2 & 1.71 & 8 & 45 & 1.5834 & 8.192 & 0.8 & 7.165 & 2.398 \\
$2^{*}$ & following & -0.3 & 1.71 & 8 & 0 & 1.821 & 8.511 & 0.3 & 6.760 & 6.394 \\
& & & & & & & & & & \\
3 & head & -171.6 & 1.925 & 15.3 & -180 & 1.9451 & 13.374 & 8.45 & 1.03 & 12.58 \\
3 & beam & -79 & 1.925 & 15.3 & -90 & 1.961 & 13.163 & 11 & 1.838 & 14.33 \\
\hline
\end{tabular}

this direction. Inherently, the estimates are in the encounter domain, but since the forward speed is zero, this is equivalent to the true domain.

From examining the Figures 9-11, it is observed that generally the estimated wave spectrum based on the heave response is closer to the measured wave spectrum than what 
the pitch estimates are. The pitch estimate is generally the best when the relative wave direction is bow or following sea. For the estimates in quartering sea for Run 1 and 3, and for head sea in Run 3, the pitch response underestimates the peak of the wave spectrum a lot, probably since the approximation of the bow as a box-shape is not accurate. Using the heave estimate for computing the significant wave height yields consistent results, with a mean estimation error for wave height of $\tilde{H}_{s}=5.79 \%$ over all directions, with a standard deviation of $3.78 \%$. The largest estimation error is $\tilde{H}_{s}=12 \%$, which occurs in Run 1 for quartering seas.
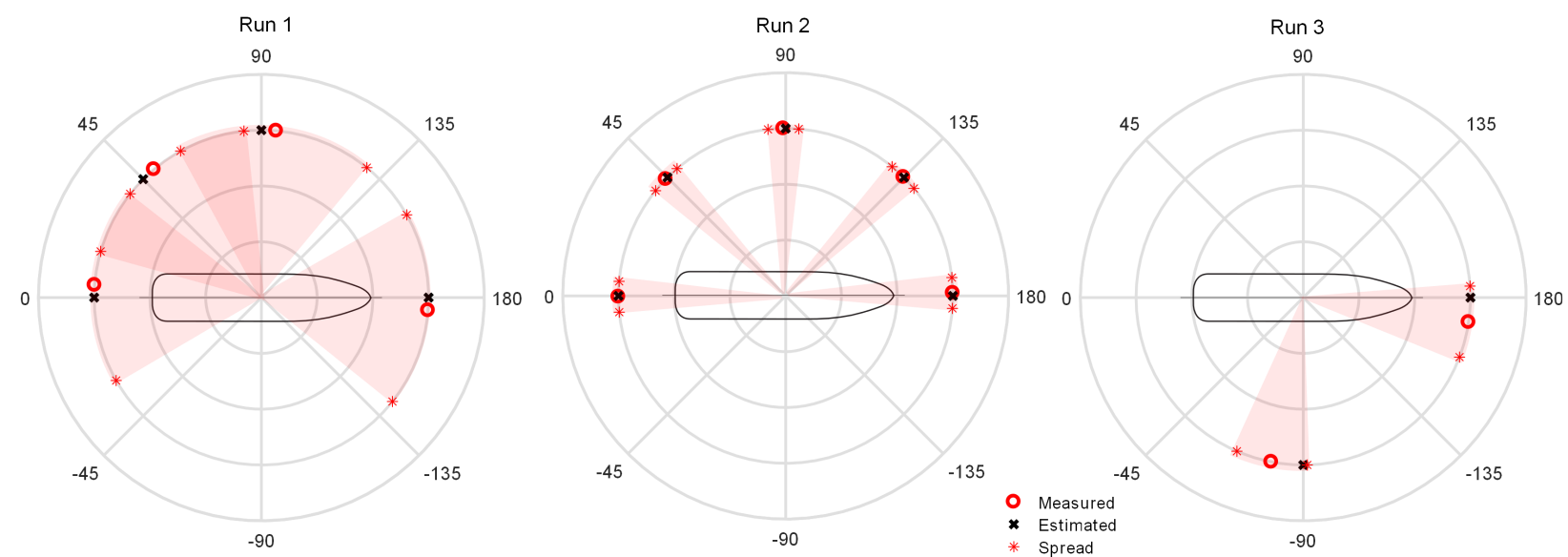

Figure 12: Measured and estimated relative wave direction $\beta$, and $\hat{\beta}$ for sea states in Runs 1-3. The spread for the sea state in Run 1 is $34^{\circ}$, so the sectors are overlapping for some directions. Keep in mind that the wave propagation direction $\Theta$ in the global frame is constant and that the vessel is changing heading.

For the two-peaked spectrum, Run 2 in Figure 10, the heave response is double-peaked for all the directional estimates, whereas the pitch peak is single-peaked for all estimates. In Table 4 the estimation errors for Run $2^{*}$, i.e., for the alternative formulation of Run 2, are stated. According to the wave measurements, there is almost the same amount of energy around the swell peak frequency as around the wind-generated wave peak frequency. However this is not reflected in the estimated wave parameters $\hat{\beta}, \hat{H}_{s}$ and $\hat{T}_{p}$, which are all (except $\hat{T}_{p}$ for head seas) estimating the wind-generated wave.

The largest estimation error for the peak period occurs for the sea state in Run 2 for head seas $\tilde{T}_{p}=30.0 \%$. Here the two-peaked heave response has a slightly higher peak 
corresponding to the swell waves, as can also be seen in Figure 10. Coincidentally, the significant wave height estimate for the same case is the best for this sea state, with $\tilde{H}_{s}=$ $1.85 \%$.

The measured relative wave direction and spread, and the estimated relative wave directions are shown in Figure 12 for all runs. The mean estimation error for the relative wave direction was $\tilde{\beta}=3.75^{\circ}$, with a standard deviation of $3.41^{\circ}$. The largest estimation error occurred for Run 3 in beam seas of $\tilde{\beta}=11^{\circ}$. However, since the test cases were for $\beta=\{0,45,90,135,180\}$, and the method is designed to estimate exactly these wave directions, the estimation error $\tilde{\beta}$ is misleading. In general the method identifies a wave direction within $45^{\circ}$ intervals, which theoretically gives a maximum estimation error of $\tilde{\beta}=22.5^{\circ}$. All relative wave directions in these test cases were identified correctly.

The waves had a relatively large spread in the first sea state of $34^{\circ}$, as seen by the overlapping sectors in Figure 12. It is not easy to detect which effects (if any) this large spread has had on the estimates. As mentioned, Algorithm 1 does not differentiate between multiple (directional) peaks, but rather makes an indirect energy-directional average, and Algorithms 2 and 3 selects the direction with the best agreement of energy. Therefore the estimated wave direction for the sea state in Run 2 corresponds fairly well for the windgenerated waves, and not at all for the swell.

\subsection{General discussion}

The procedure for estimating the sea state presented in this paper works well for the response measurements of $\mathrm{R} / \mathrm{V}$ Gunnerus in DP. The method requires little tuning in order to work, and is computationally efficient, solving $3 \times N_{\beta}$ linear equations through iteration. Here 15 minutes of response measurements were used for the response spectra, so having some overlap in the samples, a reliable sea state estimate could be available in a controller every 10 minutes, if necessary. Other parameters than the significant wave height, peak period and wave direction may be derived as input to control algorithms as well.

The DP control system kept R/V Gunnerus well in position in these data sets, which is a good basis for sea state estimation. As mentioned in Section 2.2, the size of the vessel 
compared to the waves influences the quality of the sea state estimates. Usually, the control algorithm in DP filters out the wave frequency vessel motion from the control law so that first-order wave motions are not compensated for. Hence, it is expected that DP will not actuate in the first order range, but in this case there could be some influence on the controlled surge, sway and yaw motion, since the vessel is relatively small compared to the waves. This is especially a concern for sea state estimation using the roll motion in beam sea, since the maximum roll angles for this relative wave direction are around $10^{\circ}$, and may hence be influenced by the controlled sway and yaw motions. The maximum pitch angles were generally below $5^{\circ}$, so the couplings between the controlled surge motion, and the heave and pitch motions used for estimation, are thought to be small.

The maximum heading deviation from the setpoint was $5.87^{\circ}$, which occurred in beams seas for Run 3, and the average standard deviation of the heading was $1.30^{\circ}$. These are usual values for heading deviation for moderate sea states, which is the case for the relatively small R/V Gunnerus in the data sets examined here [29]. Since the relative wave direction estimate is an energy-directional average found based on a timeseries of measurements, the influence of small oscillations in heading about the setpoint are thought to be small. The influence of the directional spread of the waves is anticipated to be much more significant. Although not shown, examination of the covariance of the response measurements reveals that the vessel is in steady state for most of the time series. However in some of the data sets the response is not stationary, so the steady-state assumption may be relaxed.

\section{Conclusion}

The sea state estimation algorithm presented in this paper is a rather direct/brute-force kind of (spectral) approach which is computationally efficient. The method requires little tuning in order to work, is computationally efficient, and relies only on the vessel responses and main vessel parameters. The method has proved so far to have excellent estimating performance, with an average significant wave height estimation error of $5.79 \%$, average peak period estimation error of $7.59 \%$, and the relative wave direction was estimated within the correct $45^{\circ}$ interval for every data set. Therefore, the method could stand alone but, due 
to its high computational efficiency, it might also be used as an 'initial sea state estimator' that gives a starting guess for some of the more established sea state estimation techniques based on Bayesian statistics or parametric optimization, e.g., [6, 11, 12, 28].

This initial study is particularly relevant for DP (no forward speed), but in the meantime the procedure has been generalized to include advance speed and short-crested waves [30]Husk å endre denne.... For future work, a sensitivity study on the number of samples in the FFT of the vessel responses, and comparing the method when using the vessel RAOs instead of the closed-form expressions could be done.

\section{Acknowledgement}

This work was supported by the Research Council of Norway through the Centres of Excellence funding scheme, project number 223254 NTNU AMOS. The data presented in this paper was collected during sea trials in 2013 in connection with the SIMVAL KPN project (grant number 225141/O70). The data collection was financed by Rolls-Royce Marine and the Norwegian Research Council through grant number 226412/O70. Thanks to Rolls-Royce Marine for permission to publish the results.

\section{References}

[1] A. J. Sørensen, A survey of dynamic positioning control systems, Annual Reviews in Control 35 (1) (2011) 123-136.

[2] M. Ludvigsen, A. J. Sørensen, Towards integrated autonomous underwater operations for ocean mapping and monitoring, Annual Reviews in Control 42 (2016) 145-157.

[3] G. F. Clauss, S. Kosleck, D. Testa, Critical situations of vessel operations in short crested seasforecast and decision support system, Journal of Offshore Mechanics and Arctic Engineering 134 (3). doi:10.1115/1.4004515.

[4] D. C. Stredulinsky, E. M. Thornhill, Ship motion and wave radar data fusion for shipboard wave measurement, Journal of Ship Research 55 (2011) 73-85.

[5] E. M. Thornhill, D. C. Stredulinsky, Real Time Local Sea State Measurement using Wave Radar and Ship Motions, in: SNAME annual meeting, Seattle, WA, USA, 2010.

[6] U. D. Nielsen, Estimations of on-site directional wave spectra from measured ship responses, Marine Structures 19 (2006) 33-69. 
[7] T. Iseki, K. Ohtsu, Bayesian estimation of directional wave spectra based on ship motions, Control Engineering Practice 8 (2) (2000) 215-219. doi:10.1016/S0967-0661(99)00156-2.

[8] R. Pascoal, C. Guedes Soares, Kalman filtering of vessel motions for ocean wave directional spectrum estimation, Ocean Engineering 36 (6-7) (2009) 477-488. doi:10.1016/j.oceaneng.2009.01.013.

[9] E. Tannuri, J. Sparano, A. Simos, J. Da Cruz, Estimating directional wave spectrum based on stationary ship motion measurements, Applied Ocean Research 25 (5) (2003) 243-261. doi:10.1016/j.apor.2004.01.003.

[10] U. D. Nielsen, A concise account of techniques available for shipboard sea state estimation, Ocean Engineering 129 (2017) 352-362. doi:10.1016/j.oceaneng.2016.11.035.

[11] C. Møgster, Sea state estimation using Bayesian modeling methods, Department for Marine Technology, (NTNU) (2015).

[12] T. Iseki, Real-time analysis of higher order ship motion spectrum, ASME. International Conference on Offshore Mechanics and Arctic Engineering, 29th International Conference on Ocean, Offshore and Arctic Engineering 2 (2017) 399-405. doi:10.1115/OMAE2010-20521.

[13] D. J. W. Belleter, R. Galeazzi, T. I. Fossen, Experimental verification of a global exponential stable nonlinear wave encounter frequency estimator, Ocean Engineering 97 (2015) 48-56. doi:10.1016/j.oceaneng.2014.12.030.

[14] A. H. Brodtkorb, U. D. Nielsen, A. J. Sørensen, Sea state estimation using model-scale DP measurements, MTS/IEEE OCEANS 2015 in Washington DC.

[15] U. D. Nielsen, M. Bjerregård, R. Galeazzi, T. I. Fossen, New concepts for shipboard sea state estimation, MTS/IEEE OCEANS 2015 in Washington DC.

[16] U. D. Nielsen, A. H. Brodtkorb, J. J. Jensen, Response predictions for marine vessels using observed autocorrelation function, To appear in: Marine Structures, 2017.

[17] J. Jensen, A. Mansour, A. Olsen, Estimation of ship motions using closed-form expressions, Ocean Engineering 31 (2004) 61-85.

[18] O. M. Faltinsen, Sea Loads on Ships and Offshore Structures, Cambridge University Press, 1993.

[19] U. D. Nielsen, Response-based estimation of sea state parameters - influence of filtering, Ocean Engineering 34 (13) (2007) 1797-1810.

[20] U. D. Nielsen, The wave buoy analogy - estimating high-frequency wave excitations, Applied Ocean Research 30 (2) (2008) 100-106.

[21] A. Papanikolaou, E. Boulougouris, D. Spanos, On the roll radius of gyration of ro-ro passenger ships, 7th International Society of Offshore and Polar Engineers (ISOPE) Conference III (1997) 499-507.

[22] S. Blagoveshchensky, Theory of Ship Motions, Dover, New York, 1962.

[23] J. Gerritsman, W. Beukelman, The distribution of hydrodynamic forces on a heaving and pitching 
shipmodel in still water, Proceedings of the Fifth Symposium on Naval Hydrodynamics, Bergen, Norway., 1964.

[24] R. Bhattacharyya, Dynamics of Marine Vehicles, John Wiley \& Sons, New York, 1978.

[25] S. Steen, Ø. Selvik, V. Hassani, Experience with rim-driven azimuthing thrusters on the research ship Gunnerus, High-Performance Marine Vessels, October 17-19 2016, Cortona, Italy.

[26] R. Skjetne, Ø. K. Kjerstad, S. A. T. Værnø, A. H. Brodtkorb, A. J. Sørensen, M. E. N. Sørensen, M. Breivik, V. Calabrò, B. O. Vinje, AMOS DP research cruise 2016: Academic full-scale testing of experimental dynamic positioning control algorithms onboard R/V Gunnerus, OMAE 2017, June, Norway.

[27] WAFO-group, WAFO - A Matlab Toolbox for Analysis of Random Waves and Loads - A Tutorial, Math. Stat., Center for Math. Sci., Lund Univ., Lund, Sweden (2000).

[28] N. Montazeri, U. D. Nielsen, J. J. Jensen, Estimation of wind sea and swell using shipboard measurements - a refined parametric modelling approach, Applied Ocean Research 54 (2016) 73 86. doi:http://doi.org/10.1016/j.apor.2015.11.004.

[29] T. I. Fossen, J. P. Strand, Passive nonlinear observer design for ships using Lyapunov methods: full-scale experiments with a supply vessel, Automatica 35 (1) (1999) 3 - 16.

[30] U. D. Nielsen, A. H. Brodtkorb, A. J. Sørensen, A brute-force spectral approach for wave estimation using measured vessel responses, To be submitted to Control Engineering Practice. 